Research Article

\title{
Involuntary Tobacco Smoking while Sailing across the Sea
}

\author{
Thomas J Luger, Janett Kreutziger, Josef Rieder and Markus F Luger \\ Department of Anesthesiology and Intensive Care Medicine, Austria
}

*Corresponding author : Thomas J Luger, Innsbruck Medical University, Department of Anesthesiology and Intensive Care Medicine, Anichstrasse 35, 6020 Innsbruck, Austria.

Received Date: January 15, 2020

Published Date: January 24, 2020

\begin{abstract}
Smoking is one of the most important factors for human health problems. Little is known about involuntary smoking effects in an outdoor sport environment, e.g. sailing. The aim of the study was to evaluate the extend of active and passive smoking during open air activities by measuring the sensitive markers of smoking namely acetonitrile, acrolein, and benzene levels in smokers and non-smokers during leisure sailing across the sea. Exhaled acetonitrile, acrolein and benzene were measured in 17 healthy male volunteers during sailboat cruises using proton transfer reaction-mass spectrometry. The time schedule consisted of a baseline evaluation, standardized measurements taken on days 1 to 6 of the cruise and following return. Additionally, the sailing conditions (wind velocity, weather, sea conditions, and boat speed) and smoking habits were charted. Exhaled acetonitrile, acrolein, and benzene were strongly increased in smokers. Furthermore, in non-smokers acetonitrile and acrolein significantly increased indicating an unexpected substantial passive smoking effect. Environmental influencing factors, e.g. automobile exhaust or adhesives could be ruled out. During sailing across the sea, involuntary smoking effects are demonstrable in non-smokers. Sailors with smoking habits should be aware of causing a substantial involuntary smoking effect for their accompanying non-smoking sailors even in an outdoor environment. .
\end{abstract}

Keywords: PTR-MS; Non-smokers; Environmental tobacco smoke effect; Acetonitrile; Benzene; Acrolein; tobacco; Passive smoking; Sailing

Abbreviations: Ptr-Ms: Proton Transfer Reaction-Mass Spectrometry; VOC: Volatile Organic Compound; ETSE: Environmental Tobacco Smoke Effect, ETS: Environmental Tobacco Smoke

\section{Introduction}

Cigarette smoke not only affects smokers but also contributes to health problems in non-smokers by involuntary smoking effects $[1,2]$. Tobacco smoke is divided into three categories. First-hand smoke describes the inhalation of tobacco by smokers, secondhand smoke the involuntary inhalation of exhaled smoke by smokers (main-stream smoke) or the release of smoke from the end of a cigarette (side-stream smoke) and three-hand smoke the inhalation of tobacco smoke residue on surfaces, furniture, clothing and carpets and gases that are left after the cigarettes have been smoked [3]. Second-hand and third-hand smoke is harmful to the health of passive smokers as seen by increasing the risk of pulmonary cancer, respiratory infections, and cardiac diseases [46]. Furthermore, it has been found that mortality in adults who never smoked but who lived with smokers was about 15\% higher than in persons who never smoked but lived in a smoke-free household [7]. In many countries all over the world smoke free areas especially in sport facilities are mandatory [8]. The protection from involuntary smoke exposure includes indoor bans. Additional research is needed for outdoor bans $[9,10]$, because no necessity is reported on sailboats and/or during leisure sailing across the sea. Therefore, the demonstration of involuntary smoking effects, e.g. in outdoor and leisure sailing activities, is of importance to nonsmoker protection.

Exhaled acetonitrile, a toxic, reactive, and irritating substance, one of the important constituents of cigarette smoke [11-13], serve as a highly specific and moderately sensitive biomarker of recent cigarette smoking with a dose-effect relationship [14,15]. The other important tobacco ingredient is benzene, a genotoxic substance described as a biomarker for exposure to environmental tobacco smoke and active smoking [16-19]. Proton transfer reactionmass spectrometry (PTR-MS) is a potential technique for analysis of trace gases down to the parts per billion (ppb) levels [14,20]. For example, it was used to measure volatile organic compounds (VOCs) during the Indian Ocean Experiment INDOEX 1999 [21] and 
in medical research [22]. Many VOCs including acetonitrile, acrolein and benzene, are breath biomarkers for active and passive smoking and correlate with actual exposure in persons exposed to tobacco smoke [17]. In addition, dramatic passive smoking effects could also be demonstrated by this method in long-distance trains [23] and in various public places in European cities, whether indoors or outdoors [24].

However, little is known about involuntary smoking effects under sailing conditions, where smokers and non-smokers are in close contact indoors and outdoors and thus non-smoking sailors are exposed to second-hand and third-hand tobacco smoke. The hypothesis of that study was that during sailing across the sea exhaled sensitive biomarkers of smoking are increased in nonsmokers who live in close contact to smokers only allowed to smoke outside the cabin. Therefore, the aim of the study was to evaluate the extend of active and involuntary smoking during open air activities by measuring acetonitrile, acrolein, and benzene levels in smokers and non-smokers during leisure sailing across the sea.

\section{Materials and Methods}

\section{Subjects and cruise description}

This prospective controlled study was approved by the Ethics Committee of Innsbruck Medical University. Enrolment criteria and follow-ups are seen in Figure 1. During two one-week sails off Italy (Sardinia) and off Greece (Kos and Santorin) 17 healthy male crew members were enrolled in this study after giving their written informed consent. Of them were eight smokers and nine non-smokers. Exclusion criteria were a history of cardiovascular or pulmonary disease as well as a respiratory infection within two weeks prior to or during the study. The crew members were familiar with sailing, but were not professionals. The sailing conditions were described in terms of medical preparedness, wind velocity, weather, sea conditions, and boat speed as reported in previous studies $[25,26]$. The sailing yachts were in Italy an „Oceanis Clipper 411” and in Greece an „Ocean star 51“. These single-hull sailboats consist of a cockpit with limited space, a small windshield and an outdoor environment, where smokers necessarily live in close proximity with non-smokers. The situation of the environmental smoke can be described by the fact that smoking was only allowed in the cockpit, which is an outdoor place protected by a small windshield. Smoking was not allowed in the cabin. Only those data obtained while sailing were analyzed; those obtained while using the boat's motor were discarded. Additionally, at sea three times daily throughout the day hemodynamic parameters and oxygen saturation were measured in a seated position after at least five minutes at rest (Figure 1).

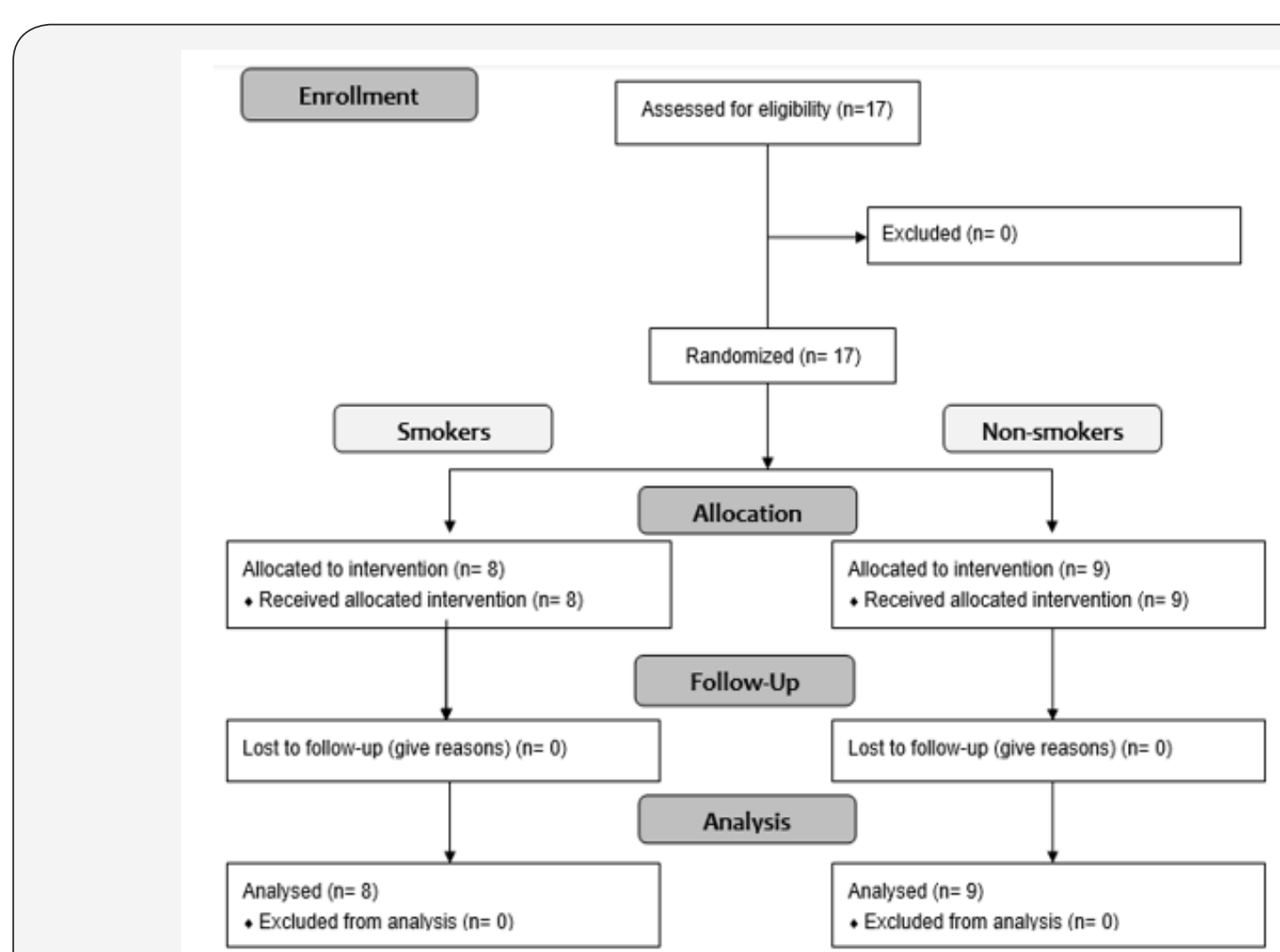

Figure 1: Enrollment of volunteers and their distribution to the groups.

\section{Experimental setup}

One day before departure each volunteer underwent baseline measurements (Baseline) and clinical examination. While sailing, samples were drawn daily throughout the trip when the individuals had not smoked for at least one hour prior to testing, were in the cockpit of the boat under sail, and were in a sitting position at rest for at least five minutes prior to testing. On day after return to home, additional samples were collected (Return data). Outdoor 
measurements were taken every day in sunny weather at the same time (midday) and place (cabin, cockpit or bow) of the boat. In detail, the sailing and weather conditions are described in Table 2. During daytime sailing, at $>3$ Beaufort non-smokers stayed together with smokers in the cockpit. Smokers did not change their [range]).

\begin{tabular}{|c|c|c|}
\hline Demographic Data & Smokers (n=8) & Non-Smokers (n=9) \\
\hline Age; years & $42.5[32-60]$ & $273-50]$ \\
\hline Body mass index; $\mathrm{kg} / \mathrm{m} 2$ & $24.6[22.1-27.3]$ & 0 \\
\hline \multicolumn{2}{|c|}{ Volunteers Smoking Habits } \\
\hline Everyday life at home & $17.5[5-30.7]$ \\
\hline While on sailing week & $19.5[5-30]$ & 0 \\
\hline & Cardiorespiratory Parameters & \\
\hline SaO $;$; mean & $97.0[95-98]$ & $97.0[94-99]$ \\
\hline MAP; mean & $93.3[75-130]$ & $86.7[70-120]$ \\
\hline HF; mean & $83.5[60-122]$ & \\
\hline
\end{tabular}

\section{Collecting samples and measurements by PTR-MS}

Exhaled air samples were collected in Tedlar® gas sampling bags (Gasco, Sarasota, FL) and measurements were made by PTRMS as previously described $[14,20,22,27]$. The first air exhaled for about five seconds was discarded and the following part of the exhaled breath was collected in a special bag having a volume of 500 to $1000 \mathrm{ml}$. The bags were stored at room temperature in a dark room. As control, three samples filled with $500 \mathrm{ml}$ nitrogen were taken along (transportation control). Ambient air was evaluated in parallel. PTR-MS combines the idea of chemical ionization with the idea of $\mathrm{H3O}$ as the primary reactant ion, which is most suitable when air samples containing a wide variety of VOC traces are to be analysed [14,27]. In PTR-MS measurements described in detail previously [14], acetonitrile is ascribed to protonated mass 42, acrolein to mass 57 and benzene to mass 79 [27]. After baseline conditions had been established, each sample was measured at least three times and the calculated average of these measurements was used for further statistical analysis.

\section{Statistical analysis}

The power analysis was based on data derived from Lindinger et al., 1998, and preliminary data from eight volunteers on a previous Italian cruise [14]. Sample size was calculated to detect a projected difference of $30 \%$ between smokers and non-smokers for a type I error of 0.05 and a power of 0.8. Thus, depending on the number of cruise participants a minimum of eight sailors were included per group. We examined the raw data separately for each volunteer and calculated baseline, sailing and post-sailing data for all subjects per group per day. Statistical analysis was performed on a Compaq computer using SPSS 11.0 for windows (SPSS Inc., 2001, Chicago, IL, USA). Following testing for normal distribution with the Kolmogorov-Smirnov test, all data are presented as median and range. The calculated concentrations are expressed in parts smoking habits while on sailing week as compared to everyday life at home (Table 1). Non-smokers had lived at home in a nonsmoking environment for at least five years and had no cigarettes or any other tobacco products on board at any time (Table 1).

Table 1: Characteristics, volunteer's smoking habits and cardiopulmonary

per billion volume (ppbv) for each subgroup. Sailing events and sailing conditions versus selected VOCs in the exhaled breath of smokers and non-smokers were calculated with linear regression analysis. Mann-Whitney U-test was performed in continuous data and chi square test for contingency tables. A $\mathrm{p} \leq 0.05$ was considered statistically significant.

\section{Result}

Demographic data and sailing conditions were comparable between groups (Table 1 and Table 2). During the 395.3 nautical miles (nm) total distance travelled, the weather was sunny, and the maximum cabin and outdoor temperature was 34.7 and $26.4{ }^{\circ} \mathrm{C}$ with a humidity of 70.2 and $42.0 \%$, respectively. Only once when sailing off Italy in the late afternoon on day 4 heavy rain did occur just before entering port (Table 2).

In smokers, the indicators - exhaled acetonitrile $(\mathrm{p}<0.001$; Figure 2), acrolein ( $<<0.01$; Figure 3$)$, and benzene $(p<0.03$; Figure 4) - were significantly different as compared to non-smokers at baseline. While sailing, smokers had elevated levels of all three indicators indicating a mainstream smoking effect. Non-smokers demonstrated significantly increased exhaled acetonitrile $(\mathrm{p}=0.03)$ and acrolein levels $(p=0.001)$ as compared to their baseline result, indicating a passive smoke effect (environmental tobacco smoke effect), which was significant on day 1, 3, 6 and 1-3, 5, 6, respectively. However, benzene levels showed a trend to an increase only ( $\mathrm{p}=0.08)$. As seen in the VOC levels of acroleine and benzene we found some evidence that in non-smokers this passive smoking effect is abundantly clear at moderate to rough sea ( $>3$ Beaufort), because under these conditions the sailors were sitting more close together in the cockpit (Table 2). However, this effect is not correlated to wind velocity and/or boat speed alone (Table 3) (Figure 2-4). 


\section{Acetonitrile (mass 42)}

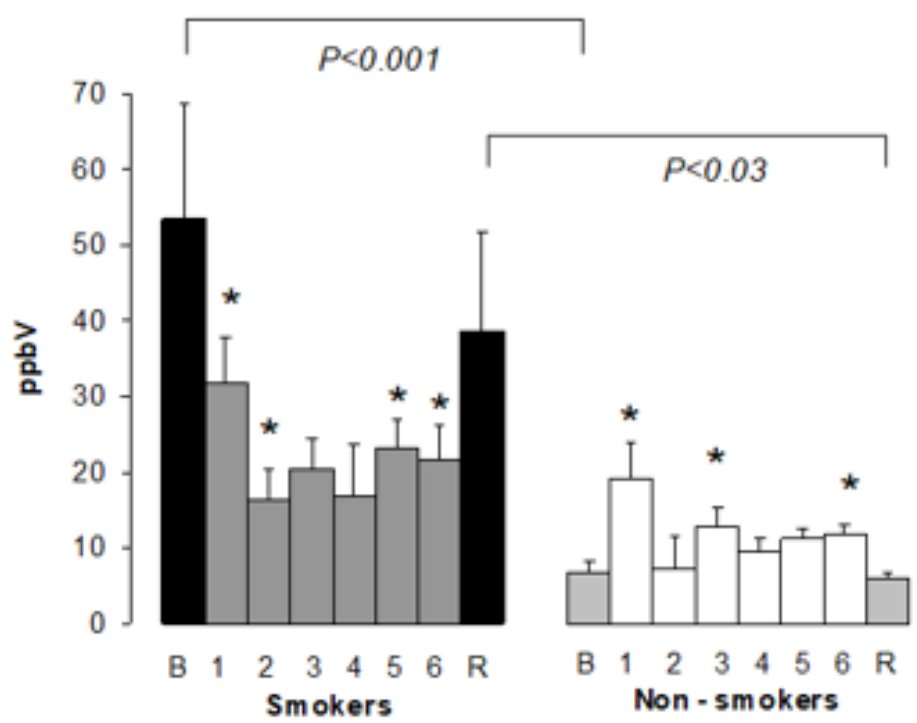

Figure 2: Exhaled acetonitrile concentrations in ppbv in non-smokers and smokers during sailing cruises. Ordinates, acetonitrile concentration presented as ppbv. Abscissa, time course: baseline, specimen drawn in Innsbruck one day before departure (B); days 1 to 6 , sailing days; return to Innsbruck, specimen drawn one day after returning to Innsbruck (R). The acetonitrile baseline, in smokers was at 38.1 [16.0 - 117.2] ppbv, which was significantly different from that of non-smokers at 5.4 [1.6 - 11.4] ppbv. In smoker's acetonitrile decreased during sailing at 16.2 [3.4 - 87.3 ppbv] but remained at high levels; in non-smokers acetonitrile significantly increased to up to 9.8 [4.6 - 61.1 ] ppbv. When the sailors were back in the urban area, in smokers it increased again to 24.3 [6.2 - 69.3] ppbv, which was again significantly different from that of non-smokers at baseline level with 5.7 [4.2 - 7.9] ppbv $(p=0.03)$. Data are expressed as median [range]. *Within groups comparison; Betweengroup differences are presented in parentheses ( $p$ values). $P \leq 0.05$.

\section{Acrolein (mass 57)}

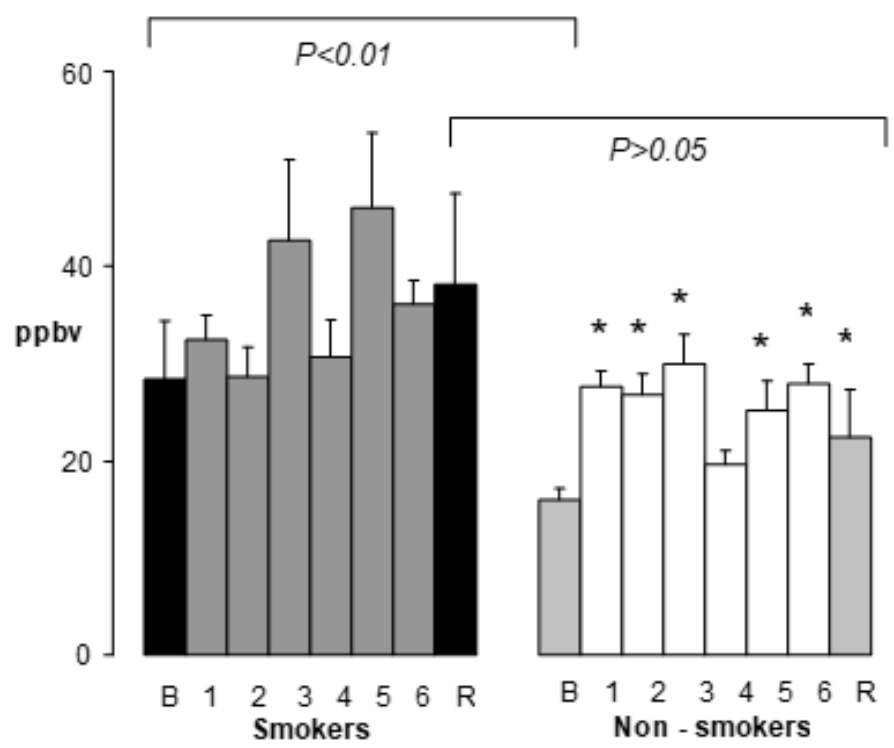

Figure 3: Time course of acrolein in air exhaled by the sailing crews. Ordinates, acrolein concentration presented as ppbv. Abscissa, time course: baseline, specimen drawn in Innsbruck one day before departure (B); days 1 to 6 , sailing days; return to Innsbruck, specimen drawn one day after returning to Innsbruck (R). In smokers exhaled acrolein baseline levels were elevated to 20.5 [15.1 - 60.5$]$ ppbv, which was significantly different from that of non-smokers at 15.4 [10.3 - 21.9] ppbv. In smokers exhaled acrolein levels remained elevated at 34.7 [18.2153.0] ppbv while sailing and after return at 30.6 [19.6 - 60.5] ppbv. In non-smokers acrolein was highly significantly increased from baseline to up to 28.2 [11.1 - 73.8] ppbv. After return, acrolein levels dropped toward baseline 23.0 [range 12.4 to 31.1 ] ppbv. Data are expressed as median [range]; *Within groups comparison; Between-group differences are presented in parentheses ( $p$ values); $p \leq 0.05$. 
Table 2: Smoking effects (VOC levels), sailing and weather conditions during the sailing weeks in the Mediterranean. $\mathrm{nm}$, nautical miles over ground. Median [range], percent or number. Mann Whitney $\mathrm{U}$ test: $\mathrm{P}<0.05$, comparisons were done ${ }^{\circ}$ between smokers and non-smokers, ${ }^{*}$ sailing groups and + within groups.

\begin{tabular}{|c|c|c|c|c|}
\hline \multicolumn{3}{|c|}{ Sailing Conditions } & Italy & Greece \\
\hline \multicolumn{3}{|c|}{ Total sailing distance $(\mathrm{nm})$} & 132.8 & 262.5 \\
\hline \multicolumn{3}{|c|}{ Solely under sail (\%) } & 60.3 & 92.5 \\
\hline \multicolumn{3}{|c|}{ Under motor alone (\%) } & 27.6 & 6.9 \\
\hline \multicolumn{3}{|c|}{ Sails and motor (\%) } & 12.1 & 0.6 \\
\hline \multicolumn{3}{|c|}{ Daily sailing distance $(\mathrm{nm})$} & $21.2[9.4-32.8]$ & $41.5[34.1-57.8]$ \\
\hline \multicolumn{3}{|c|}{ Boat speed (knots) } & $3.5[3.2-7.7]$ & $8.4[6.9-10.1]$ \\
\hline \multicolumn{3}{|c|}{ Maximum } & 10.1 over 300 feet & 13.9 over 329 feet \\
\hline \multicolumn{3}{|c|}{ Wind velocity (knots) } & $3.5[2-9]$ & $14.5[13-26]$ \\
\hline \multicolumn{3}{|c|}{ Beaufort } & $1[1-3]$ & $4.5[4-6]$ \\
\hline \multicolumn{3}{|c|}{ Sea } & $2[1-4]$ & $4[3-6]$ \\
\hline \multirow{9}{*}{ Smoker } & \multirow{6}{*}{ Acrolein } & Base & Acetonitrile & $16.7[16.0-120.2]$ \\
\hline & & Sailing & $17.6[3.4-51.8]^{\circ}$ & $16.6[11.7-87.3]$ \\
\hline & & Return & $24.2[6.2-69.3]$ & $12.9[5.7-20.3]$ \\
\hline & & Base & $41.6[37.8-60.5]^{\circ}$ & $15.7[15.1-21.3]^{*}$ \\
\hline & & Sailing & $31.6[18.2-61.3]^{\circ}$ & $37.4[18.9-88.2]+$ \\
\hline & & Return & $25.1[19.6-60.5]$ & $36.6[16.8-53.3]+$ \\
\hline & \multirow{3}{*}{ Benzene } & Base & $7.3[1.4-21.8]$ & $1.9[1.4-5.7]$ \\
\hline & & Sailing & $3.5[0.9-18.8]^{\circ}$ & $4.6[2.6-13.7]^{\circ}$ \\
\hline & & Return & $2.8[1.8-21.8]$ & $4.4[2.8-7.1]$ \\
\hline \multirow{9}{*}{ Non-Smoker } & \multirow{3}{*}{ Acetonitrile } & Base & $4.2[3.5-9.8]$ & $10.7[1.6-11.4]$ \\
\hline & & Sailing & $7.3[4.6-14.0]^{\circ}$ & $13.7[8.0-61.1]^{*}$ \\
\hline & & Return & $5.7[4.2-7.9]$ & $13.1[8.7-24.3]^{*}$ \\
\hline & \multirow{3}{*}{ Acrolein } & Base & $17.8[14.0-19.4]^{\circ}$ & $13.6[10.3-21.9]$ \\
\hline & & Sailing & $25.8[11.1-49.6]^{\circ}+$ & $30.3[17.7-73.8]+$ \\
\hline & & Return & $19.9[15.3-31.2]$ & $31.4[16.8-38.6]+$ \\
\hline & \multirow{3}{*}{ Benzene } & Base & $1.0[0.9-2.1]$ & $1.6[1.3-2.0]$ \\
\hline & & Sailing & $1.6[0.7-7.9]^{\circ}+$ & $3.3[1.7-10.7]^{* o_{+}}$ \\
\hline & & Return & $1.8[6.2-69.3]+$ & $3.7[2.2-5.4]^{*_{+}}$ \\
\hline
\end{tabular}

Table 3: Sailing events and sailing conditions versus selected VOCs in the exhaled breath of smokers and non-smokers during sailboat cruises in the Mediterranean. N: number of samples, R: regression coefficient, Sign: significance, $P \leq 0.01$.

\begin{tabular}{|c|c|c|c|c|c|c|}
\hline \multicolumn{4}{|c|}{ Smokers $(\mathrm{N}=32)$} & \multirow{2}{*}{\multicolumn{3}{|c|}{$\begin{array}{c}\text { Non-smokers }(\mathrm{N}=53) \\
\text { R Spearman's Sign coefficient }\end{array}$}} \\
\hline & \multicolumn{3}{|c|}{ R Spearman's Sign coefficient } & & & \\
\hline \multicolumn{7}{|c|}{ Wind velocity versus } \\
\hline Acetonitrile & 0.02 & 0.004 & 0.98 & 0.03 & -0.07 & 0.65 \\
\hline Acrolein & 0.09 & 0.13 & 0.49 & 0.1 & -0.02 & 0.87 \\
\hline Benzene & 0.12 & 0.3 & 0.51 & 0.03 & 0.16 & 0.27 \\
\hline \multicolumn{7}{|c|}{ Boat speed versus } \\
\hline Acetonitrile & 0.01 & 0.07 & 0.73 & 0.03 & -0.05 & 0.74 \\
\hline Acrolein & 0.1 & 0.08 & 0.67 & 0.12 & -0.13 & 0.39 \\
\hline Benzene & 0.12 & 0.23 & 0.22 & 0.04 & 0.08 & 0.75 \\
\hline Wind velocity & 0.99 & 0.84 & $0.0001^{*}$ & 0.99 & 0.84 & $0.0001^{*}$ \\
\hline
\end{tabular}




\section{Benzol (mass 79)}

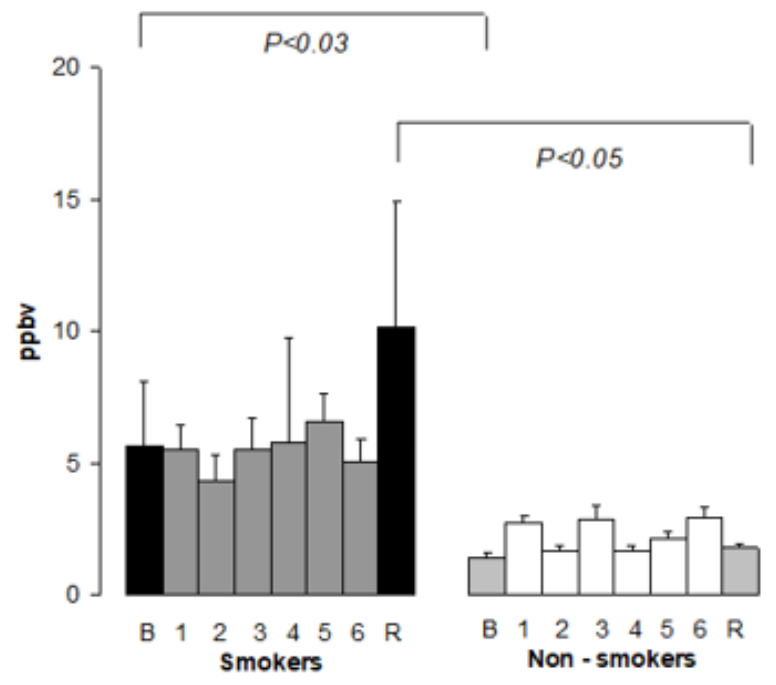

Figure 4: Time course of benzene in air exhaled by the sailing crews. Ordinates, benzene concentration presented as ppbv. Abscissa, time course: baseline, specimen drawn in Innsbruck one day before departure (B); days 1 to 6 , sailing days; return to Innsbruck, specimen drawn one day after returning to Innsbruck (R). At baseline smokers demonstrated significantly elevated exhaled benzene levels at 3.1 [1.4 - 21.8] ppbv as compared to non-smokers at 1.4 [0.9 and 2.1] ppbv. Smokers' benzene levels did not change under sailing conditions at 4.5 [0.9 to 18.8] ppbv or after return at 2.8 [1.8 - 21.8] ppbv. In non-smokers benzene levels showed with 2.1 [0.7 - 10.7] ppbv only a trend to an increase during sailing and was after return with 1.8 [1.4 - 2.1] ppbv again at baseline level. Data are expressed as median [range]. *Within groups comparison; Between-group differences are presented in parentheses ( $p$ values); $P \leq 0.05$.

Outdoor measurements taken at sea and in the urban area were comparable indicating that environmental factors, e.g. automobile or ship exhaust, could be ruled out as influencing factors (sea level versus urban area: acetonitrile, 3.9 [2.5-21.5] versus 9.1 [7.0-11.2] ppbv; acrolein, 13.7 [7.7-39.8] versus 14.9 [14.2-15.6] ppbv and benzene, 1.1 [0.8-4.0] versus 1.4 [1.3-1.4] ppbv). Probes (3 per day) taken in the cockpit (entrance to the cabin) during the sailing cruise showed acetonitrile at 4.8 [2.9-26.8] ppbv, acrolein at 14.7 [8.7-44.2] ppbv and benzene at 1.2 [0.8-3.8] ppbv indicating that no effects of boat materials, like adhesive sealing materials were seen that may contribute to our findings. Transportation effects do not contribute to our findings since the control values for the observed parameters in the gas sampling bags were low (acetonitrile: 3.6 [2.6-4.7] ppbv; acrolein: 16.3 [12.8-19.8] ppbv; benzene: 1.3 [1.11.5] ppbv).

\section{Discussion}

Mainstream smoking effect. PTR-MS demonstrated that smokers had very significantly elevated levels of exhaled acetonitrile indicating a first-hand smoke effect. These results obtained while sailing support previous observations made in an urban area, namely that in smokers' acetonitrile typically ranges between 30 and 100 ppbv and in non-smokers between 5 and 10 ppbv [12,14]. However, in smokers who did not change their smoking habits it is likely that the reduction in acetonitrile observed between baseline and sailing may be related to inhalation of fresh air rather than only reduced smoking at sea. Additionally, smokers showed benzene levels between 1.4 and 21.8 ppbv, meaning that benzene is significantly enhanced in smokers [28]. Similar effects were also seen in blood samples, showing that smoking is associated with exposure to VOCs, in particular benzene and toluene [29]. Thus, these high levels of both biomarkers in smokers seem to be related mainly to mainstream smoking $[18,30]$. It must be kept in mind that acetonitrile is found in organic combustion products, cigarette smoke, automobile and industrial exhaust and is thus present in the atmosphere in the gas phase [31]. Benzene is present in cigarette smoke and automobile exhaust fumes [27]. At sea, outdoor measurements taken in the atmosphere showed significantly decreased levels of acetonitrile and benzene. Furthermore, the ports of call were not industrial, but agricultural. Therefore, it is unlikely that other factors such as automobile exhaust, industrial activities or manufacturing contributed to our finding [29,31]. Additionally, in smokers wind velocity and boat speed can be ruled out as a possible bias in our measurements, because no correlation was found between these parameters and VOC levels (Table 3). Transportation effects were also seen to not contribute to our findings since the control values of all parameters were low. A limitation in interpreting the results may be the small sample size. However, even in such a small collective significant difference were observed in acetonitrile and benzene levels between smokers and non-smokers, indicating that both biomarkers may serve as a means of detecting active tobacco smoking.

Involuntary smoking effect. Moreover, in non-smokers acetonitrile increased significantly while sailing in an outdoor environment, indicating a relevant involuntary smoking effect. For the non-smokers on board this finding is indicative of a involuntary tobacco smoke effect $[13,30]$ unrelated to their origin as a secondhand and/or third-hand smoke. A strong correlation was seen between cigarettes smoked per day and acetonitrile concentration 
[14]. Thus, the proximity of active and passive cigarette smokers on board, the lack of environmental sources as well as the strong correlation between cigarettes smoked per day and acetonitrile concentration [14] [lindinger 1998] suggest cigarette smoking as the causative factor. The fact that significant increases in acetonitrile were found in non-smokers means that acetonitrile may be a highly specific biomarker for environmental tobacco smoke effect. Even under sailing conditions the acetonitrile concentration in exhaled breath measured by PTR-MS was clearly seen to be a useful, fast and simple means of detecting cigarette smoking including passive smoking. By contrast, benzene levels in non-smokers showed only a trend, indicating a failure to detect a passive smoking effect. This finding stands in contrast to that of Scherer \& Richter, 1997, who described benzene as a biomarker for exposure to environmental tobacco smoke effect [18]. This discrepancy may be explained by the method used and the fact that smoking was refrained from for at least one hour, while when not smoking benzene levels decreased to the levels of non-smokers within about one hour [14]. Thus, the PTR-MS data in this study demonstrate that benzene may be effective in measuring mainstream smoking effects but may not be useful in detecting passive smoking effects.

The mechanisms for potential impact of second-hand and thirdhand smoke during sailing were the limited space in the cockpit, the sailing clothing, boat surfaces, sailing at conditions $>3$ Beaufort and/or the fact that especially under these conditions non-smoking crew members lived in close quarters with smokers. However, as a single item we did not observe a correlation between wind velocity or boat speed and the concentrations of the study markers. It should be kept in mind that the cockpit of this sailboat (single hull) with rough boat surfaces was an outdoor environment with limited space and a small windshield; thus, windy conditions were present to only a limited extent. Nevertheless, Klepeis et al., 2007, found that under certain wind conditions outdoor tobacco smoke levels also approached zero at distances greater than approximately two meters from a single cigarette [32]. During periods of active smoking, peak and average outdoor tobacco smoke levels near smokers rivaled indoor tobacco smoke concentrations [32]. In our study smokers were not allowed to smoke in the cabin, and therefore during the cruises smoking was possible only in the boat's outdoor environment, e.g. the cockpit, and thus necessarily in close proximity with non-smokers. The air flow may remove the smell of tobacco smoke but does not eliminate all the carcinogenic particles and gases from the air, clothing, surfaces etc, as was observed for pub ventilation [33]. All these facts, namely the proximity to smokers, the sailing activities, clothing and the sailing boat's limited space and surfaces, govern second-hand and/or third-hand smoke effect exposure. Moreover, our findings were made in a single-hull sailboat. Therefore, the conclusions drawn from our study may differ from those for other categories of sailboat with different design and available space, for example catamarans and trimarans.

Limitations. First, some potential methodological limitations of the study are the partly rather small sample sizes. Taking the proportion of the sample sizes of smokers and non-smokers into account, the statistically confirmed differences appear to be more relevant. Another limitation is the fact that the ions at certain $\mathrm{m} / \mathrm{z}$ values can represent various substances or rather fragments. However, PTR-MS has been shown as an excellent screening tool before $[22,29]$ and is sufficient to answer specific scientific questions (20). Third, separate measurements of potential thirdhand smoke effects were not performed in either groups because we only wanted to demonstrate an involuntary smoke effect independent of their origin. This interesting topic would be of interest for further studies.

\section{Conclusion}

Simply by evaluating acetonitrile (as well as acrolein and benzene) in an outdoor environment (sailboat cockpit) a recent involuntary smoke effect was detected in non-smokers, indicating that during sailing across the sea with smokers second-hand and/ or third hand smoking still occur. These observations may also have consequences for their health. Involuntary smoke causes or exacerbates a wide range of adverse health effects, including cancer, a range of respiratory diseases including asthma, and heart disease. Even in young and healthy men and women, smoking is negatively related to cardiovascular fitness and heart rate response to exercise, and in men the adverse effects of smoking become stronger with increasing age [34]. The reasons why amateurs enjoy sailing as a leisure sport are recreation, stress relief and improved health. From this practical point of view, although respecting the smoking habits of many sailors we recommend that smokers should be aware of causing an involuntary smoking effect for their accompanying non-smoking sailors in an outdoor environment on board, e.g. the cockpit. Tobacco control strategies should be considered in protecting non-smokers from second-hand and third-hand smoke [9]. Additionally, we conclude that analysis of exhaled -breath acetonitrile and acrolein may provide a basis for non-invasive assessment of tobacco smoke effects.

\section{Acknowledgment}

We thank the crew members on the sailing yachts off Italy and Greece who were not authors, but gave their written informed consent, namely Johannes Giner, Franz Hausberger, Rainer Lugmayr, Alois Wach, Wilfried Zingerle, Romed Unsinn, Thomas Pollak, Dieter Zoller, Romed Giner, Markus Wille and especially Gunther Hackh, the skipper on the Italian cruise, and Kurt Krenn, the skipper of the Greek cruise for their cooperation. We thank Florian Perner and Dietmar Bader for support concerning PTR-MS measurements. This research was supported in part by a FWF grant P-14149-MED (J. Rieder).

\section{Contributors}

TJL conceived the study, identified the data, performed preliminary analysis and wrote the draft manuscript. ML assisted with identifying the data and statistical analysis as well as contributed to drafting and finalizing the manuscript. JR and JK contributed to drafting the manuscript and proofreading. 


\section{Funding}

This research was carried out at the Innsbruck Medical Universities and supported in part by the FWF grant P-14149-MED (J. Rieder).

\section{Competing Interests}

None declared.

\section{Conflict of Interest}

No author has a conflict of interest with regard to drugs or devices used in this study.

\section{References}

1. Invernizzi G, Boffi R, Ruprecht A, Lazzaro A, Fabbri LM (2008) Passive smoking and asthma death. Eur Respir J 32(4): 1117-1133.

2. Howard J (2004) Smoking is an occupational hazard. Am J Ind Med 46(2): 161-169.

3. (2007) World Health Organization (WHO) Protection from exposure to secondhand tobacco smoke. Policy recommendations. WHO press, Geneva, Switzerland.

4. Bentayeb M, Simoni M, Norback D, Baldacci S, Maio S, et al. (2013) Indoor air pollution and respiratory health in the elderly. J Environ Sci Health Part A 48(14): 1783-1789.

5. Janson C, Chinn S, Jarvis D, Zock JP, Torén K, et al. (2001) Effect of passive smoking on respiratory symptoms, bronchial responsiveness, lung function, and total serum IgE in the European Community Respiratory Health Survey: a cross-sectional study. Lancet 358(9299): 2103-2109.

6. Brownson RC, Eriksen MP, Davis RM, Warner KE (1997) Environmental tobacco smoke: health effects and policies to reduce exposure. Annu Rev Public Health 18: 163-185.

7. Invernizzi G, Ruprecht A, Mazza R, Marco CD, Boffi R (2004) Transfer of particulate matter pollution from smoking to non - smoking coaches: the explanation for the smoking ban on Italian trains. Tob Control 13(3):3 19-320.

8. Hyland A, Barnoya J, Corral JE (2012) Smoke-free air policies: past, present and future. Tob Control 21(2):154-161.

9. Semple S, Mueller W, Leyland AH, Gray L, Cherrie JW (2018) Assessing progress in protecting non-smokers from secondhand smoke. Tob Control 28(6):692-695

10. Barnoya J, Navas-Acien A (2013) Protecting the world from secondhand tobacco smoke exposure: where do we stand and where do we go from here? Nicotine Tob Res 15(4): 789-804.

11. Pinggera GM, Lirk P, Bodogri F, Herwig R, Steckel-Berger G, et al. (2005) Urinary acetonitrile concentrations correlate with recent smoking behaviour. BJU Int 95(3): 306-309.

12. Lirk P, Bodrogi F, Deibl M, Kähler CM, Colvin J, et al. (2004) Quantification of recent smoking behaviour using proton transfer reaction-mass spectrometry (PTR-MS). Wien Klin Wochenschr 116(1-2): 21-25.

13. Campbell JK, Rhoades JW, Gross AL (1963) Acetonitrile as a constituent of cigarette smoke. Nature 198: 991-992.

14. Lindinger W, Hansel A, Jordan A (1998) On-line monitoring of volatile organic compounds at pptv levels by means of proton-transfer-reaction mass spectroscopy (PTR-MS). Medical applications, food control and environmental research. Int J Mass Spectrom Ion Processes 173: 191241.
15. Houeto P, Hoffman JR, Got P, Dang VuB, Baud FJ (1997) Acetonitrile as a possible marker of current cigarette smoking. Hum Exp Toxicol 16(11): 658-661.

16. Baker RR, Massey ED, Smith G (2004) An overview of the effects of tobacco ingredients on smoke chemistry and toxicity. Food Chem Toxicol 42 Suppl: S53-83.

17. Gordon SM, Wallace LA, Brinkman MC, Callahan PJ, Kenny DV (2002) Volatile organic compounds as breath biomarkers for active and passive smoking. Environ Health Perspect 110: 689-698.

18. Scherer G, Richter E (1997) Biomonitoring exposure to environmental tobacco smoke (ETS): a critical reappraisal. Hum Exp Toxicol 16: 449459.

19. Burns D (1991) Cigarette and cigarette smoking. Clin Chest Med 12(4): 631-642.

20. Sekimoto K, Li SM, Yuan B, Koss A, Coggon M, et al. (2017) Calculation of the sensitivity of proton-transfer-reaction mass spectrometry (PTR-MS) for organic trace gases using molecular properties. Int J Mass Spectrom 421: 71-94.

21. Lelieveld J, Crutzen PJ, Ramanathan V, Andreae MO, Brenninkmeijer CM, et al. (2001) The Indian Ocean Experiment: Widespread Air Pollution from South and Southeast Asia. Science 291(5506): 1031-1036.

22. Herbig J, Amann A (2009) Proton transfer reaction-mass spectrometry applications in medical research. J Breath Res 3(2): 020201.

23. Hill S, Blakely T, Kawachi I Woodward A (2004) Mortality among „never smokers "living with smokers: two cohort studies, 1981-4 and 1996-9. BMJ 328(7446): 988-999.

24. Nebot M, Lopez MJ, Gorini G, Neuberger M, Axelsson S, et al. (2005) Environmental tobacco smoke exposure in public places of European cities. Tob Control 14(1): 60-63.

25. Luger TJ, Giner R, Lorenz IH (2001) Cardiological monitoring of sailors via offshore Internet connection. J Sports Med Phys Fitness 41(4): 486490.

26. Luger TJ, Peham D, Mayr B, Groemer G, Luger MF (2011) Medical Preparedness and Long-Distance Leisure Catamaran Sailing. Science \& Sports 26: 174-178.

27. Hansel A, Jordan A, Holzinger R, Lindinger W (1995) Proton transfer reaction-mass spectrometry: on-line trace gas analysis at the ppb level. Int J Mass Spectrom Ion Process 149-150: 609-619.

28. Wester RC, Maibach HI, Gruenke LD, Craig JC (1986) Benzene levels in ambient air and breath of smokers and nonsmokers in urban and pristine environments, J. Toxicol Environ Health 18(4): 567-573.

29. Wallace L (1996) Environmental exposure to benzene: an update. Environ Health Perspect 104(Suppl 6): 1129-1136.

30. Nazaroff WW, Singer BC Inhalation of hazardous air pollutants from environmental tobacco smoke in US residences. J Expo Anal Environ Epidemiol 14(Suppl 1): S71-77.

31. Howard G (1990) Passive smoking is an industrial injury. Occup Health (Lond) 42(11):328-329.

32. Klepeis NE, Ott WR, Switzer P (2007) Real-time measurement of outdoor tobacco smoke particles. J Air Waste Manag Assoc 57(7): 522-534.

33. Carrington J, Gee IL, Watson AFR (2003) The effects of smoking status and ventilation on environmental tobacco smoke concentrations in public areas of UK pubs and bars. Atmos Environ 37: 3255 - 3266.

34. Bernaards CM, Twisk JWR, Van Mechelen W, Snel J, Kemper HC (2003) A longitudinal study on smoking in relationship to fitness and heart rate response. Med Sci Sports Exerc 35(5): 793-800. 